\title{
Oral and Dental Health
}

Open Access

\section{The Dental Surgeon Profile of Centers of Dental Specialties for the Evidence of Burnout Syndrome}

\section{Stephanie Albuquerque de Souza Brandão ${ }^{1}$, Gabriel Silveira Pinto Brandão², Luciane Albuquerque Sá de Souza ${ }^{3}$ and Camila Santos de Mattos brito ${ }^{1}$}

${ }^{1}$ UNIPÊ-University Center of João Pessoa, Brazil

${ }^{2}$ Institute of Sciences of FUNORTE/SOEBRAS, Brazil

${ }^{3}$ Uninassau-João Pessoa, Brazil

*Corresponding author: Stephanie Albuquerque de Souza Brandão, UNIPÊ-University Center of João Pessoa, Rua José Patrício de Almeida, 79/102. Jardim Oceania, João Pessoa, Paraíba, Brazil

\begin{abstract}
Introduction: The persistence and intensity of stressors, in addition to the characteristics and functions of each person, associated with efforts and failures to deal with stress and its consequences, can lead the worker to develop chronic labor exhaustion, reaching the most severe form of stress at work, the burnout. The dental surgeon is a victim of stress sources in the public sector.
\end{abstract}

Objective: Identify the dentists who work in the Centers of Dental Specialties (CDSs) in the municipalities of João Pessoa and Cabedelo in Paraíba, Brazil, which are more likely to develop Burnout Syndrome (BS).

Methodology: The quantitative approach was chosen, with a descriptive character, with data collection via structured questionnaire (socio-demographic data and MBI-HSS).

Results: Thirty dentists volunteered, the majority being female (63.3\%); Age group above 35 years $(80 \%) ; 70 \%$ have Specialization; $13.3 \%$ Master's Degree, $6.7 \% \mathrm{PhD}$ and $10 \%$ have another type of postgraduate degree. BS is a state of fatigue or frustration caused by dedication to a cause, a lifestyle, or a relationship that has failed to generate expected reward. It is not necessarily the result of overwork, but it configures a gap between the effort made and the reward received. Multidimensional syndrome or construct characterized by three components: Emotional/physical Exhaustion (EE), Depersonalization (DE), and Decreased Personal Accomplishment/personal involvement in work (PA).

Discussion: The dental surgeons who work in the CDSs: $6.7 \%$ showed signs of SB; $30 \%$ are at high risk; $20 \%$ in medium risk; and $43.3 \%$ at low risk of acquiring SB. They had high and medium level of EE and DE: $26.7 \%$ had high scores in the EE dimension (imbalance between individual and work, generating physical and emotional exhaustion), and $23.3 \%$ in DE dimension (consequence of emotional exhaustion); Already in the PA there was $50 \%$ of low level, being this dimension the most striking and worrying, to be analyzed inverted. CDSs intervention programs are needed, including prevention and control of BS, as well as developing coping skills to help professionals handle stressful work situations. There is an improvement in the social context and working conditions of those involved because it is not only an individual but an organizational problem.

\section{Introduction}

Some work activities have their own characteristics that end up exposing workers to events that can lead to lower quality of life at work, as well as greater mental suffering when compared to other professions. This is the case of dentists who are subject to life-threatening situations [1], as well as having to deal with precarious working conditions resulting from a sometimes-deficient public structure.

The persistence and intensity of the stressors, as well as the characteristics and functions of each person, associated with the various efforts and failures to deal adequately with the stress and its consequences, can lead the worker to develop a reaction of chronic labor exhaustion [2]. In this sense, if the worker does not deal with stressors, it is undeniable that he can suffer deleterious effects on his physical and psychological

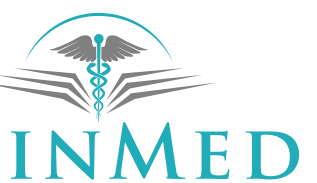

INTERNATIONAL LIBRARY

Citation: de Souza Brandão SA, Brandão GSP, de Souza LAS, de Mattos brito CS (2018) The Dental Surgeon Profile of Centers of Dental Specialties for the Evidence of Burnout Syndrome. Int J Oral Dent Health 4:075. doi.org/10.23937/2469-5734/1510075

Accepted: December 24, 2018: Published: December 26, 2018

Copyright: (C) 2018 de Souza Brandão SA, et al. This is an open-access article distributed under the terms of the Creative Commons Attribution License, which permits unrestricted use, distribution, and reproduction in any medium, provided the original author and source are credited. 
health, especially when it comes to the most severe form of stress at work, Burnout [3].

The dentist has been pointed out in the literature [4] as a vulnerable professional to occupational risk, due to the characteristics peculiar to his professional performance. Although this syndrome isn't well explored in the Brazilian literature [5], some authors [6-8] talk about high prevalence of Burnout among dentists, resulting in low professional satisfaction and consequent decrease in productivity and quality of services provided [9], thus generating negative consequences for the quality of life in the work of these professionals.

Thus, the objective of this research was to identify the dentists who work in the Centers of Dental Specialties (CDSs) in the counties of João Pessoa and Cabedelo in Paraíba (Brazil) who are more likely to develop Burnout Syndrome.

\section{The Burnout Syndrome}

In Brazil, this syndrome was officially included in diseases related to workers' health through Decree No. 3,048, dated May 6, 1999. In item XII of Annex II, in the table of "Mental Disorders and Behavior Related to Work", the "State of Vital Exhaustion" is a synonym of Burnout, due to occupational risk factors such as "hard work" and "Other physical and mental difficulties related to work" [10].

The term stress was used for the first time in the seventeenth century to describe distress, oppression, suffering and adversity [11]. Stress has a broad meaning and is understood as being "The set of reactions of the organism to physical, psychic, infectious and other aggressions, capable of disturbing the homeostasis" [12].

There are several types of stress and, among them, the so-called occupational stress, referring to the professional activities of the people. This type of stress stands out from the others, particularly when dealing with its most extreme form, the withdrawal syndrome [2] or Burnout [11], an expression meaning "to be consumed by fire" [13]. Some scholars argue that Burnout emerged as a social problem [14]. For them, Burnout came to be described in the literature as a psychological syndrome, coming from a frequent emotional tension, experienced by professionals who need to constantly relate to people who need assistance. In this way, from a psychosocial perspective, Burnout syndrome is understood as a process, in which aspects of the work and interpersonal context contribute effectively and significantly to its development [15].

It is a multidimensional syndrome or construct characterized by three components: 1) Emotional and/ or physical exhaustion; 2) Depersonalization, and 3) Decreased personal achievement $[11,13,15,16]$. The first concerns the feelings of fatigue and the reduction of the emotional resources fundamental so that the person can deal with the stressful situation [16]. The second dimension is a dynamic process manifested mainly by the development of negative attitudes and feelings, skepticism, insensitivity, disrespect and disregard for people related to work $[13,15]$. The third component can be perceived by the loss of the feeling of accomplishment in the work with low productivity [15].

Although this syndrome is not yet widely explored in the Brazilian literature [5], some researchers [6-8] talk about the high prevalence of the syndrome among dentists, which results in low professional satisfaction and consequent drop in productivity and quality of services provided [9], thus generating negative consequences for the quality of life in the work of these professionals. It is confirmed, therefore, that Burnout Syndrome is a response to chronic work stress that occurs mainly in professions that focus on service delivery, as is the case of dentists [17].

\section{The Centers of Dental Specialties (CDSs)}

The Centers of Dental Specialties (CDSs) are health establishments that participate in the National Registry of Health Establishments (NRHE), considered as a specialized clinic. The treatment offered in these places is a continuation of the work carried out by the primary care network and, in this case, the municipalities that are in the Family Health Strategy by the oral health teams [18].

\section{Methodology}

The present study was carried out in the cities of João Pessoa and Cabedelo, in the state of Paraiba, Brazil, from June to September 2018. The research was developed in the dependencies of the Centers of Dental Specialties (CDSs), provided with 06 (six) units.

For the data collection, two questionnaires, anonymous and self-administered, were used. The first one consisted of 13 closed questions for the survey of sociodemographic variables. The second questionnaire comprises the Maslach and Jackson inventory questions, the Maslach Burnout Inventory-Human Services Survey (MBI-HSS), developed to evaluate Burnout Syndrome in its three dimensions, and was validated in Brazil by Carlotto, Câmara [19].

The data were classified, categorized, organized and evaluated [20] with the purpose of generating interpretations that led to the attainment of the general objective proposed by this work. The data was entered in the Microsoft Excel 2016 (version 1708) and statistical calculations were performed through the same program. After analyzing the data, the results were presented in graphs and tables. 


\section{Results}

Thirty dentists were volunteers. The majority were female $(63.3 \%)$, older than 35 years $(80 \%)$, married $(73.3 \%)$ and with children $(70 \%)$. It was observed that $70 \%$ have specialization; $13.3 \%$ did masters; $6.7 \%$ already have a doctorate; and $10 \%$ have another type of postgraduate course, having an average professional time of more than 31 years (36.7\%).

Regarding their employment relationship, 53.3\% of the respondents are partially self-employed professionals with employment ties in other places (as in the case of this survey, the CDSs). $23.3 \%$ of the dental surgeons who participated in this research work 40 hours a week, while another $23.3 \%$ work 60 hours a week. When talking about the average number of patients attended, $26.6 \%$ of the professionals attend 21 to 30 patients a week, while another $26.6 \%$ attend more than 51 patients per week.

As far as sleep is concerned, $60 \%$ of professionals say they can get a good night's rest and $86.7 \%$ say they have never left work because of stress, scam or depression. In the question of having or not oral service assistant, the clear majority (96.55\%) said that they received help in their care. Regarding the care of the person with special needs, $46.7 \%$ of dental surgeons stated that they perform such care.

All the results can be seen in the Table 1.

Thus, according to the data analysis, the results indicated that, of the dentists working in the CDSs: $6.7 \%$ already had evidence of Burnout Syndrome. It was observed that $30 \%$ of participants had a high risk of developing this syndrome; $20 \%$ of dental surgeons present medium risk, since there was a dimension outside the cutoff point; and, finally, $43.3 \%$ have a low chance of manifesting any signs of this syndrome, because they presented medium or low EE, medium or low DE and medium or high PA.

The participants had high and medium level of EE and DE: $26.7 \%$ had high scores in the EE dimension (imbalance between individual and work, generating physical and emotional exhaustion), and $23.3 \%$ in DE dimension (consequence of emotional exhaustion); Already in the PA there was $50 \%$ of low level, being this dimension most striking and worrying, to be analyzed in

Table 1: Participant's scores on the risk of burnout.

\begin{tabular}{|c|c|c|c|c|c|c|c|c|c|c|}
\hline & \multicolumn{2}{|l|}{ EE } & \multirow{2}{*}{\begin{tabular}{|l} 
DE \\
Score
\end{tabular}} & \multirow[b]{2}{*}{ Level } & \multirow{2}{*}{$\begin{array}{l}\text { PA } \\
\text { Score }\end{array}$} & \multirow[b]{2}{*}{ Level } & \multicolumn{4}{|c|}{ Burnout syndrome } \\
\hline & Score & Level & & & & & Bournout & High risk & Medium risk & Low risk \\
\hline R1 & 42 & $\mathrm{H}$ & 13 & $\mathrm{H}$ & 25 & $L$ & $x$ & & & \\
\hline R2 & 17 & $M$ & 5 & $M$ & 32 & $\mathrm{~L}$ & & & $x$ & \\
\hline R3 & 24 & $M$ & 7 & M & 33 & $\mathrm{~L}$ & & & $x$ & \\
\hline R4 & 37 & $\mathrm{H}$ & 12 & $\mathrm{H}$ & 31 & $L$ & $x$ & & & \\
\hline R5 & 25 & $M$ & 8 & $M$ & 24 & $\mathrm{~L}$ & & & $x$ & \\
\hline R6 & 12 & $L$ & 5 & M & 23 & $\mathrm{~L}$ & & & $x$ & \\
\hline R7 & 20 & $M$ & 6 & M & 35 & M & & & & $x$ \\
\hline R8 & 27 & $\mathrm{H}$ & 6 & $M$ & 14 & $\mathrm{~L}$ & & $x$ & & \\
\hline R9 & 41 & $\mathrm{H}$ & 13 & $\mathrm{H}$ & 35 & M & & $x$ & & \\
\hline R10 & 12 & L & 5 & $M$ & 38 & $M$ & & & & $x$ \\
\hline R11 & 24 & $M$ & 5 & $M$ & 35 & $M$ & & & & $x$ \\
\hline R12 & 20 & $M$ & 8 & $M$ & 23 & $\mathrm{~L}$ & & & $x$ & \\
\hline R13 & 20 & $M$ & 11 & $\mathrm{H}$ & 28 & $L$ & & $x$ & & \\
\hline R14 & 15 & L & 5 & $M$ & 39 & $M$ & & & & $x$ \\
\hline R15 & 18 & $M$ & 11 & $\mathrm{H}$ & 28 & $L$ & & $x$ & & \\
\hline R16 & 35 & $\mathrm{H}$ & 8 & $M$ & 30 & $\mathrm{~L}$ & & $x$ & & \\
\hline R17 & 13 & $\mathrm{~L}$ & 5 & $M$ & 36 & $M$ & & & & $x$ \\
\hline R18 & 15 & $\mathrm{~L}$ & 5 & $M$ & 36 & $M$ & & & & $x$ \\
\hline R19 & 16 & $M$ & 5 & $M$ & 39 & $M$ & & & & $x$ \\
\hline R20 & 25 & $M$ & 13 & $\mathrm{H}$ & 33 & $L$ & & $x$ & & \\
\hline R21 & 31 & $\mathrm{H}$ & 6 & $M$ & 30 & $\mathrm{~L}$ & & $x$ & & \\
\hline R22 & 19 & $M$ & 5 & $M$ & 37 & $M$ & & & & $x$ \\
\hline R23 & 12 & $\mathrm{~L}$ & 5 & $M$ & 38 & $M$ & & & & $x$ \\
\hline R24 & 20 & $M$ & 5 & $M$ & 39 & $M$ & & & & $x$ \\
\hline R25 & 28 & $\mathrm{H}$ & 8 & $M$ & 31 & $\mathrm{~L}$ & & $x$ & & \\
\hline R26 & 22 & $M$ & 5 & $M$ & 30 & $L$ & & & $x$ & \\
\hline R27 & 12 & $\mathrm{~L}$ & 5 & $M$ & 38 & $M$ & & & & $x$ \\
\hline R28 & 9 & L & 5 & $M$ & 39 & $M$ & & & & $x$ \\
\hline R29 & 13 & L & 5 & $M$ & 38 & $M$ & & & & $x$ \\
\hline R30 & 35 & $\mathrm{H}$ & 12 & $\mathrm{H}$ & 36 & $M$ & & $x$ & & \\
\hline Total & & & & & & & 2 & 9 & 6 & 13 \\
\hline$\%$ & & & & & & & 6.7 & 30.0 & 20.6 & 43.3 \\
\hline
\end{tabular}

Levels: H (High); M (Medium); L (Low). 
Table 2: Relationship between risk levels.

\begin{tabular}{|l|l|l|l|l|l|l|}
\hline & EE & \multicolumn{3}{l|}{ DE } & \multicolumn{3}{l|}{ PA } \\
\cline { 2 - 8 } & $\mathbf{n}$ & $\%$ & $\mathbf{n}$ & $\%$ & $\mathbf{n}$ & $\%$ \\
\hline High & 8 & 26.7 & 7 & 23.3 & 0 & 0.0 \\
\hline Medium & 13 & 43.3 & 23 & 76.7 & 15 & 50.0 \\
\hline Low & 9 & 30.0 & 0 & 0.0 & 15 & 50.0 \\
\hline Total & 30 & 100.0 & 30 & 100.0 & 30 & 100.0 \\
\hline
\end{tabular}

an inverted way (Table 2).

\section{Discussion}

The data of Table 1 was analyzed, seeking inspiration in the proposal of Ebisui [21] considering that:

- A high EE indicator, either high in DE, or low in PA is indicative of risk to the occurrence of the syndrome, generating a point of risk score;

- Subjects with 03 points, that is, outside the cut-off point in the three dimensions (high EE, high DE and low PA) are in burnout;

- People with 02 dimensions outside the cut-off point indicate $(\mathrm{H})$ high risk of burnout;

- Individuals with 01 dimension outside the cut-off point indicate (M) medium risk of Burnout.

Subjects with indices below the limits (present medium or low EE, medium or low DE and medium or high $\mathrm{PA}$ ) have (L) low risk of presenting the syndrome.

The manifestation of Burnout syndrome, according to the MBI-HSS, could be confirmed because it was verified the presence of this triad: High level $E E$, high level DE and low-level PA. When Burnout is manifested, the professional presents as physical and mental exhaustion, as well as being unable to continue with his projects, reporting heavy fatigue and triggering emotional and relationship problems in personal and professional life [22].

As it was the dimension that stood out from the results, the reduced PA will be explored with more emphasis. According to Benevides-Pereira [23], the professional begins to show dissatisfaction with the work activities that he performs, feeling of inadequacy, low self-esteem, a sense of professional failure and demotivation, generating low efficiency in work. In addition, the surgeon-dentist with such characteristics can present impetus of abandonment of employment, having, according to Schaufeli, Buunk [24], dysfunctional attitudes and behaviors.

From the results presented, in general, it was verified that $6.7 \%$ are already compromised and that $50 \%$ of the participants already present some type of evidence, indicating medium or high risk of these professionals to develop this syndrome. According to Lipp [25], there are five stages of Burnout Syndrome:

- First phase (or Idealism): Energy and enthusiasm are unlimited; Work seems to fulfill all needs and desires. The clinic is the most crucial factor for the dental surgeon;

- Second phase (or Realism): it is perceived by the professional that the initial expectations were unrealistic. Clinical activities do not meet all needs. Rewards and recognition are scarce, and disappointment increases. The professional works, but becomes more tired and frustrated, starting to question their own competence and skills to attend, losing self-confidence;

- Stage Three (Stagnation and Frustration/NearBurnout): Enthusiasm and early energies turn into chronic fatigue and irritability toward colleagues and managers. Habits are changed and escape behaviors such as delays, and faults can occur. The productivity and the quality of the work are reduced. The dentist becomes increasingly frustrated, blaming patients, colleagues and managers for the difficulties;

- Fourth phase (or Apathy and Total Burnout): feeling of despair, failure and loss of self-esteem. Professional becomes depressed and feels lonely and empty. Life loses meaning, paralyzing pessimism about the future settles in. Dentist wants to leave work, feeling physically and emotionally exhausted;

- Fifth phase (or Phoenix Phenomenon): It does not always occur; However it is possible that the professional has resilience and resuscitate as a phoenix of the ashes of his Burnout Syndrome.

It is suggested that the managers of the Centers of Dental Specialties (CDSs) of the municipalities of João Pessoa and Cabedelo adopt measures of interventions to minimize or prevent the progression of the syndrome and future pathologies related to mental health. It is necessary to adopt organizational strategies applied to the work environment, as well as individual strategies focused on the responses of professionals in the attempt to regulate their emotions in the face of stressful situations and, also, combined strategies with focus on the interaction of the organizational environment with the dental surgeons (involving the professionals, the patients and the managers of the CDSs). For those who are already committed to Burnout, coping strategies are recommended to slow down symptoms, such as: Using a sense of humor, using relaxation techniques, improving eating habits (eating vegetables and fruits) and practicing physical activity [26].

According to National Jewish Health [27], some other ways to deal with stress at work are:

- Keep a positive attitude;

- Accept that there are events that cannot be controlled;

- Learn to relax;

- Rest and sleep well; 

them.

Find the stressors and effective ways to cope with

The Burnout syndrome coping proposals should be elaborate according to the necessity of each person/group that was committed by the syndrome. Environmental adjustments must be made to reduce the adverse effects in an organizational level and to get a better professional's response of the workplace [26].

In this way, it is necessary to research, disseminate and expand the alternatives for the prevention and treatment of Burnout Syndrome in dental surgeons, and not only focus on the difficulties and problems of the management and structure of the public workplace, since they are all part of the process of environmental improvement, and comprehensive intervention is required for quality service and interaction.

\section{References}

1. Te Brake H, Smits N, Wicherts JM, Gorter RC, Hoogstraten J (2008) Burnout development among dentists: A longitudinal study. Eur J Oral Sci 116: 545-551.

2. Formighieri VJ (2003) Burnout em fisioterapeutas: Influência sobre a atividade de trabalho e bem-estar físico e psicológico.

3. Maslach C (2003) A multidimensional theory of burnout. In: CL Cooper, Theories of organizational stress. Oxford University Press, New York, 68-85.

4. Drutman J (2001) Burnout o el "incendio" de los trabajadores de la salud. Revista Odontología Ejercicio Profesional 2: 100-105.

5. Carlotto MS, Câmara SG (2008) Análise da produção científica sobre a síndrome de burnout no Brasil. Psico 39: 152-158.

6. Lima ADF, Farias FLR (2005) O trabalho do cirurgiãodentista e o estresse: Considerações teóricas. RBPS 18: 50-54.

7. Garbin CAS, Saliba O, Gonçalves PE (2006) Síndrome de Burnout: O estresse do cirurgião-dentista moderno. Rev Assoc Paul Cir Dent 60: 131-133.

8. Murtomaa H, Haavio-mannila E, Kandolin I (1990) Burnout and its causes in finnish dentists. Community Dent Oral Epidemiol 18: 208-212.

9. Campos JADB, Trotta OST, Bonafé FSS, Maroco J (2010) Burnout em dentistas do serviço público: Ter ou não ter, eis a questão! Rev Odontol UNESP 39: 109-114.

10. Brasil (1999) Ministério da previdência e assistência social. Aprova o regulamento da previdência social, e dá outras providências.
11. Reinhold HH (2004) O sentido da vida: Prevenção de stress e burnout do professor. PUC-Campinas.

12. Gouveia VV, Barbosa GA, Massud M (2007) Bem-estar e saúde mental. In: GA Barbosa, EO Andrade, MB Carneiro, VV Gouveia, A saúde dos médicos no Brasil, 29-48.

13. Oliveira GF (2008) Trabalho e bem-estar subjetivo: Compreendendo a situação laboral dos médicos. Tese de doutorado, Universidade federal da paraíba/universidade federal do rio grande do norte.

14. Schaufeli W, Enzmann D (1998) The burnout companion to study and practice. London.

15. Borges LO, Argolo JCT, Pereira ALS, Machado EAP, Silva WS (2002) A síndrome de burnout e os valores organizacionais: Um estudo comparativo em hospitais universitários. Psicol Reflex Crit 15: 189-200.

16. Gil-Monte PR (2003) Burnout syndrome: Síndrome de quemarse por el trabajo, desgaste profesional, estrés laboral o enfermedad de Tomás?

17. Souza SAS, Souza LAS, Lima Júnior MAV (2017) Síndrome de burnout: O cirurgião- dentista docente e o esgotamento laboral crônico. Revista Campo do Saber 3: 1-10.

18. Ministério da saúde (2018) Centro de especialidades odontológicas.

19. Carlotto MS, Câmara SG (2007) Propriedades psicométricas do maslash burnout inventory em uma amostra multifuncional. Psicol estud 24: 325-332.

20. Barros AJS, Lehfeld NS (2000) Fundamentos da metodologia científica. ( $2^{\text {nd }}$ edn $)$, ampliada, pearson makron books, São Paulo, Brazil.

21. Ebsui CTN (2008) Trabalho docente do enfermeiro e a síndrome de burnout: Desafios e perspectivas. USPRibeirão Preto.

22. Rossi AM, Perrewe PL, Sauter SL (2005) Stress e qualidade de vida no trabalho: Perspectivas atuais da saúde ocupacional.

23. Benevides-Pereira AMT (2002) Burnout: O processo de adoecer pelo trabalho. Benevides-pereira AMT burnout: Quando o trabalho ameaça o bem-estar do trabalhador. Casa do Psicólogo, São Paulo, 21-91.

24. Schaufeli WB, Buunk BP (2003) Burnout: An overview of 25 years of research an theorizing. In: Schabracq MJ, Winnusbst JAM, Cooper CL, The handbook of work and health psychology. John Wiley \& Sons Ltd, New York, 383-425.

25. Lipp M (2006) O stress do professor. ( $4^{\text {th }}$ edn), Campinas, Brazil.

26. Moreno FN, Gil GP, Haddad MCL, Vannuchi MTO (2011) Estratégias e intervenções no enfrentamento da síndrome de burnout. Rev enferm 19: 140-145.

27. National jewish health. Coping strategies. 